\title{
Validity and Reliability of the Problem Solving Inventory (PSI) in a Nationwide Sample of Greek Educators
}

\author{
Ntina Kourmousi ${ }^{1, *}$, Vasiliki Xythali ${ }^{1,2}$, Maria Theologitou ${ }^{2}$ and Vasilios Koutras ${ }^{2}$ \\ 1 Primary Education Directorate of Eastern Attica, 150 Lavriou Ave \& 4 Andrikou str., 15454 Glyka Nera, \\ Greece; vaxythal@sch.gr \\ 2 Early Childhood Education, University of Ioannina, P.O. Box 1186, 45110 Ioannina, Greece; \\ mtheol@sch.gr (M.T.); vkoutras@cc.uoi.gr (V.K.) \\ * Correspondence: nkourmousi@sch.gr; Tel.: +30-693-274-3222
}

Academic Editor: Martin J. Bull

Received: 27 December 2015; Accepted: 10 June 2016; Published: 15 June 2016

\begin{abstract}
The Problem Solving Inventory (PSI) is designed to measure adults' perceptions of problem-solving ability. The presented study aimed to translate it and assess its reliability and validity in a nationwide sample of 3668 Greek educators. In order to evaluate internal consistency reliability, Cronbach's alpha coefficient was used. The scale's construct validity was examined by a confirmatory factor analysis (CFA) and by investigating its correlation with the Internality, Powerful others and Chance Multidimensional Locus of Control Scale (IPC LOC Scale), the Rosenberg Self-Esteem Scale (RSES) and demographic information. Internal consistency reliability was satisfactory with Cronbach's alphas ranging from 0.79 to 0.91 for all PSI scales. CFA confirmed that the bi-level model fitted the data well. The root mean square error of approximation (RMSEA), the comparative fit index (CFI) and the goodness of fit index (GFI) values were 0.030, 0.97 and 0.96 , respectively, further confirming the bi-level model and the three-factors construct of the PSI. Intercorrelations and correlation coefficients between the PSI, the IPC LOC Scale and the RSES were significant. Age, sex, and working experience differences were found. In conclusion, the Greek version of the PSI was found to have satisfactory psychometric properties and therefore, it can be used to evaluate Greek teachers' perceptions of their problem-solving skills.
\end{abstract}

Keywords: problem-solving; reliability; validity; confirmatory factor analysis; teachers/educators; Greek sample; PSI

\section{Introduction}

Problem-solving refers to the cognitive, affective and behavioral processes and to the particular set of skills people employ in order to find solutions for the challenges of everyday life [1,2]. Many studies have focused on the association between problem-solving, mental health and psychological adjustment [2-4], since poor problem-solving abilities have been linked to stress, depression, maladaptive behavior and even physical health symptoms [2,4]. Therefore, problem-solving skills seem to be quite useful for many clinicians who focus on behavior therapy and strive to empower people in order to increase their life satisfaction and ameliorate their well-being [3,5,6]. It can also be a useful tool for many practitioners such as educators [1], since they could use it not only for their students' training and psychosocial improvement, but for their own socio-emotional and life improvement as well.

Problem Solving Inventory. On the basis of Butler and Meichenbaum's [7] hypothesis that an individual's appraisal of one's problem-solving skills will affect one's problem-solving performance and the whole problem-solving process, Heppner and Petersen [8] developed the Problem Solving 
Inventory (PSI). The PSI is a widely used instrument which assesses perceived problem-solving competence, as a review of over 120 studies has shown [2]. It measures perceptions of one's problem-solving ability, also including behaviors and attitudes associated with problem-solving styles [1]. It yields three underlying dimensions, Problem-Solving Confidence, Approach-Avoidance Style, and Personal Control. Not only are these factors intercorrelated, but they have been proven to be distinct dimensions [9].

Critique on the PSI has been made regarding difficulty in the interpretation of the scale scoring due to lack of specificity regarding what constitutes "high" or "low" scores, questionable interpretation of its three scales as measuring independent aspects of problem-solving behavior, weak evidence for the long-term stability of the Personal Control Scale, and, more seriously, inadequacy of the normative data for the general population [10] and need for a sounder psychometric base using larger and more diverse samples [11]. However, the cultural validity of PSI, as well as its internal consistency, have been supported by many studies which have been conducted in Italian high school students [12], Mexican American high school students [13], adolescents in Hong Kong [14] and Nigeria [15], college students in Midwestern USA [8], Australian college students [16], Turkish college students [17], South African college students [18], African American college students [19], French Canadian adults [20] and Romanian adults [21]. Such a research has not been carried out in Greece, hence the current study's effort to validate PSI in a Greek adult sample, as a part of a larger survey investigating the impact of Problem Solving Confidence, Self-Esteem, and Locus of Control on the Self-Efficacy of educators of different teaching levels, job statuses, specialties, positions and training. In the presented paper, locus of control and self-esteem were investigated in order for the convergent validity of the PSI to be checked.

Problem-solving and locus of control. There is some research evidence suggesting that people who feel they can control elements of their life conditions also tend to be better at solving their problems [8,22]. Early on, Rotter [23] has supported that when people expect that they can affect-to some extent-what happens to them, their attitude towards their problem-solving ability becomes more positive. Successful problem-solvers are not impulsive; they do not avoid, but rather deliberately strategize how to approach a problem, always being confident in their ability to solve it, as they tend to attribute causality to internal and controllable factors [24] and have an internal locus of control [8]. The fact that PSI consists of items measuring the confidence in problem-solving skills and the personal control—both central concepts in locus of control—further supports their interconnection.

Problem-solving and self-esteem. Butler and Meichenbaum [7] emphasized the role of self-appraisals on an individual's problem-solving ability. A poor problem-solving ability could be associated with lower self-esteem; it has already been mentioned that problem solving can predict a wide range of psychological adjustment factors, such as self-esteem [1]. The appraisals of one's problem-solving skills may be indicative of how the individual approaches the hardships he or she encounters in life and may also play an important role in psychological health [1,9].

\section{Methods}

\subsection{Participants}

The sample consisted of 3668 educators of all levels and specialties who completed the measures described in 2.2. Sample characteristics are shown in Table 1. Of the participants, 1030 were men $(28.1 \%)$ and 2638 were women $(71.9 \%)$. The mean age was $44.4(\mathrm{SD}=8.7) ; 31.5 \%$ were above 40 years old, $36.4 \%$ belonged to the $41-49$-year-old age group, and $32.2 \%$ were older ( $\geqslant 50$ years old). The majority was married $(63 \%)$ and the mean number of working years at school was $14.9(\mathrm{SD}=9.5)$. Most of the teachers worked in the public sector $(89.1 \%)$, mostly full-time $(90.6 \%)$, while few worked in private educational institutions $(10.9 \%)$ and part-time $(9.4 \%)$. Concerning their educational level, two out of three educators (66.9\%) had a Bachelor degree, almost one third held a Master $(28.9 \%)$, and a small number a Ph.D. (4.2\%). 
Table 1. Sample characteristics.

\begin{tabular}{|c|c|}
\hline Personal and Job-Related Characteristics & $\mathrm{N}(\%)$ \\
\hline \multicolumn{2}{|l|}{ Sex } \\
\hline Men & $1030(28.1)$ \\
\hline Women & $2638(71.9)$ \\
\hline Age, mean (SD) & $44.4(8.7)$ \\
\hline \multicolumn{2}{|l|}{ Age } \\
\hline$\leqslant 40$ & $1147(31.5)$ \\
\hline $41-49$ & $1326(36.4)$ \\
\hline$\geqslant 50$ & $1174(32.2)$ \\
\hline \multicolumn{2}{|l|}{ Family status } \\
\hline Single & $1015(27.8)$ \\
\hline Married & $2298(63.0)$ \\
\hline Separated & $74(2.0)$ \\
\hline Divorced & $226(6.2)$ \\
\hline Widowed & $34(0.9)$ \\
\hline Years of working experience at school, mean (SD) & $14.9(9.5)$ \\
\hline \multicolumn{2}{|l|}{ School } \\
\hline Public & $3267(89.1)$ \\
\hline Private & $401(10.9)$ \\
\hline \multicolumn{2}{|l|}{ Higher degree } \\
\hline Bachelor & $2452(66.9)$ \\
\hline Master & $1059(28.9)$ \\
\hline Ph.D. & $154(4.2)$ \\
\hline \multicolumn{2}{|l|}{ Working status } \\
\hline Part time & $344(9.4)$ \\
\hline Full time & $3324(90.6)$ \\
\hline
\end{tabular}

\subsection{Measures}

Problem Solving Inventory. The Problem Solving Inventory (PSI) [8] is a 35-item instrument (3 filler items) that measures the individual's perceptions regarding one's problem-solving abilities and problem-solving style in the everyday life. As such, it measures a person's appraisals of one's problem-solving abilities rather than the person's actual problem-solving skills. It consists of three factors, thus yielding three separate subscales. Problem-Solving Confidence (11 items) assesses self-perceived confidence, belief and self-assurance in effectively solving problems (e.g., "I am usually able to think up creative and effective alternatives to solve a problem."). Higher scores on PSC are associated with lower levels of problem-solving confidence. Approach-Avoidance Style (16 items) assesses whether individuals tend to approach or avoid problems (e.g., "When a solution to a problem was unsuccessful, I do not examine why it didn't work."). Higher scores reflect a style of avoiding rather than approaching problems. Personal Control (5 items) assesses elements of self-control on emotions and behavior (e.g., "I make snap judgments and later regret them."). Higher scores on PC reflect a more negative perception of personal control on one's problems. All items are scored on a six-point Likert scale, ranging from $1=$ Strongly Agree to $6=$ Strongly Disagree. A total score can be calculated as a general index of problem-solving appraisal that ranges from 32 to 192. Lower scores on each factor and on the total PSI score are considered more functional.

Locus of Control. The original Multidimensional Locus of Control IPC Scale [25-27] includes 24 items which measure an individual's locus of control. Items are scored on a six-point Likert scale, which ranges from -3 (Strongly Disagree) to +3 (Strongly Agree). The scale consists of three distinct dimensions: (a) the Internality subscale, which measures the degree of a person's confidence in his/her 
own abilities and the potency to control the outcome of his/her life's events; (b) the Powerful Others subscale, which evaluates the degree to which a person feels that his/her life is controlled by people of power; and (c) the Chance subscale that investigates the perceptions of luck and fate determining a person's life. Each subscale generates a unique score by adding up its eight responses as well as a constant of +24 , in order to eliminate negative sums. Therefore, each respondent receives three scores (ranging from 0 to 48 ) according to his/her beliefs on each of the three dimensions' subjects. The Greek version of the Multidimensional Locus of Control IPC Scale, which has been found to have satisfactory psychometric properties, was used in the present study [28].

Self-esteem. The Rosenberg Self-Esteem Scale (RSES) [29] is one of the most widely used and well-validated measures of global self-esteem. It assesses general feelings of self-acceptance and self-worth by items such as "On the whole, I am satisfied with myself". It includes 10 items, scored on a four-point Likert scale, ranging from $0=$ Strongly Disagree to $3=$ Strongly Agree. It produces a total score ranging from 0 to 30, with scores between 15 and 25 considered normal and high scores indicating higher levels of self-esteem. The Greek version, which has been found to have satisfactory psychometric properties, was used in the present study [30].

Demographic information. Participating teachers were asked to provide personal information such as age, sex, education level, and family status, and also work-related data such as the type of educational organization (private or public) they worked for, their working experience, and their working status (part-time or full-time).

\subsection{Procedure}

The research took place during the school year of 2014, from April to June. All the measures, in the form of an electronic booklet, were posted on the official Greek site for schools and educators [31] (to which $99.98 \%$ of elementary and secondary schools are linked), on various official sites of teachers' associations (i.e., www.pekade.gr, www.p-e-f.gr, www.inital.gr, etc.) and on all the relevant educational sites (i.e., www.specialeducation.gr, www.alfavita.gr, www.omep.gr, etc.), in the span of several days. After choosing to open a link titled "Do you want to find out your scores on Self Esteem, Emotional Intelligence and Problem-Solving?" [32], the participating teachers were informed about the aim of the study and the questionnaire's structure on the first opening page. On the same page they were ensured about the anonymity maintaining taken measures and they were let to know that they would get material relevant to the aforementioned skills, along with their personal scores, upon questionnaire completion. The information package included information on the factors which affect these traits, as well as general recommendations and instructions on how to improve them.

\subsection{Translation}

The PSI was translated from its original form into the Greek language, as recommended in the literature review $[33,34]$. Two professional translators who were native speakers of the Greek language (i.e., target) and were also fluent in the English language (i.e., source) proceeded with independent forward translations of the target language. The preliminary Greek version developed was translated back into the origin language by another professional translator. The two versions, the back-translation and the original one, were compared and modifications were made where discrepancies between the two were found. Afterwards, the produced scale was reviewed by an expert committee who gave their feedback, and then was administered to a small group of volunteering teachers, who helped to further evaluate the clarity and comprehension of the questionnaire's items. After this, the final Greek version which is described below was produced.

\section{Statistical Analysis}

To test the first hypothesis that the PSI assesses one general factor as well as three specific factors, the bi-level model was examined via confirmatory factor analysis (CFA). According to Heppner et al. [18], a bi-level model was indicated as the best representative model. Specifically, 
the bi-level model consists of three first-order factors (i.e., PSC, AAS, and PC) and the second-order factor is one general factor (i.e., PSI). That is, each indicator (e.g., PSI items) loads on both a general factor and on one of the three specific factors of the PSI. An item bundling (or parcelling) procedure was carried out as in Heppner et al.'s study [18], where the authors divided the items from the three PSI factors into nine bundles (three bundles for PSC, four bundles for AAS, and two bundles for PC). The same factor structure was tested in the current study. On the basis of factor loadings for each factor, the items were rank-ordered and assigned to bundles in order to equate the average loadings of each bundle on each factor. Because of the unequal number of items in each bundle, the average scores were used to form each bundle. The fit of the CFA model was assessed using the chi square $\left(\chi^{2}\right)$, the comparative fit index (CFI), the goodness of fit index (GFI) and the root mean square error of approximation (RMSEA) [35]. For the CFI and GFI indices, values close to or greater than 0.95 are taken to reflect a good fit to the data [36]. RMSEA values of less than 0.05 indicate a good fit and values as high as 0.08 indicate a reasonable fit [36]. Similarly, a non significant chi square statistic indicates a good fit, but chi square is usually sensitive to sample sizes and usually significant for large sample sizes as ours [35]. The scale's internal consistency reliability was determined by the calculation of Cronbach's $\alpha$ coefficient. Scales with reliabilities equal to or greater than 0.70 were considered acceptable. Validity was further examined by using the correlations (Pearson's r) between the PSI subscales and the RSES and IPC LOC dimensions. Correlation coefficients between 0.1 and 0.3 are considered low, between 0.31 and 0.5 moderate and above 0.5 high. Differences of sex and age on PSI subscales were investigated by using Student's t-test and analysis of variance (ANOVA), respectively. In order to control for multiple testing, the Bonferroni correction was used. Additionally, Pearson's correlation coefficients were used to explore the relationship of PSI subscales with years of working experience at school. The p-values reported are two-tailed and the statistical significance level was set at 0.05. The analyses were conducted with the SPSS and AMOS (SPSS, Chicago, IL, USA) Statistical Software.

\section{Results}

\subsection{Internal Consistency Reliability}

Descriptive statistics and Cronbach's alpha coefficients for the PSI scales are shown in Table 2. All the PSI subscales exceeded the minimum reliability standard of 0.70. Specifically, Cronbach's alpha was 0.90 for Problem Solving Confidence, 0.89 for Approach-Avoidance Style, 0.79 for Personal Control and 0.91 for total PSI score. The mean value for Problem Solving Confidence was 25.4 (SD = 7.8), for Approach-Avoidance Style was 38.5 (SD = 11.8), for Personal Control was $14.6(\mathrm{SD}=5.1)$ and for total PSI score was $78.5(\mathrm{SD}=21.7)$.

Table 2. Mean values, correlations, intercorrelations and Cronbach's alpha coefficients for the Problem Solving Inventory subscales.

\begin{tabular}{|c|c|c|c|c|c|c|c|c|}
\hline & \multirow[t]{2}{*}{ Mean } & \multirow[t]{2}{*}{ SD } & \multirow[t]{2}{*}{ Minimum } & \multirow[t]{2}{*}{ Maximum } & \multirow[t]{2}{*}{$\begin{array}{l}\text { Cronbach's } \\
\text { Alpha }\end{array}$} & \multicolumn{3}{|c|}{$\begin{array}{l}\text { Correlation } \\
\text { Coefficients }\end{array}$} \\
\hline & & & & & & & 2. & 3. \\
\hline 1. Problem Solving Confidence & 25.4 & 7.8 & 11 & 61 & 0.90 & & & \\
\hline 2. Approach-Avoidance Style & 38.5 & 11.8 & 16 & 87 & 0.89 & 0.62 & & \\
\hline 3. Personal Control & 14.6 & 5.1 & 5 & 30 & 0.79 & 0.61 & 0.67 & \\
\hline 4. Total PSI score & 78.5 & 21.7 & 32 & 169 & 0.91 & 0.84 & 0.93 & 0.82 \\
\hline
\end{tabular}

Note: $p$-value $<0.001$ for all correlation coefficients. 


\subsection{Intercorrelations}

The intercorrelations of the PSI subscales are shown in Table 2. All scales were significantly correlated with each other. The correlations among Problem Solving Confidence, Approach-Avoidance Style and Personal Control were above 0.60. Similarly, as expected, the correlations of the aforementioned factors with the total PSI score were very high.

\subsection{Results from CFA}

A CFA was conducted to test the bi-level model for the study sample. The chi-square test was significant, as expected, which was almost certainly due to the large sample size $\left(\chi^{2}=507.7, p<0.05\right)$. The RMSEA, CFI and GFI values were 0.030, 0.97 and 0.96, respectively, indicating that the bi-level model fitted the data well. Factors loadings were high and ranged from 0.71 to 0.91 .

\subsection{Convergent Validity}

Correlation coefficients of the PSI subscales with the IPC LOC Scale and the RSES are shown in Table 3. All correlations were found significant. The PSI subscales correlated negatively with Internality, but positively with Powerful Others and Chance. Additionally, correlations between PSI subscales and the RSES were negative, indicating that higher levels of self-esteem are associated with better problem solving ability.

Table 3. Correlation coefficients of the Problem Solving Inventory subscales with IPC Locus of Control (LOC) Scale and the Rosenberg Self-Esteem Scale (RSES).

\begin{tabular}{lllll}
\hline & Internality & Powerful Others & Chance & Self-esteem \\
\hline Problem Solving Confidence & -0.54 & 0.41 & 0.38 & -0.62 \\
Approach-Avoidance Style & -0.34 & 0.44 & 0.38 & -0.46 \\
Personal Control & -0.30 & 0.54 & 0.46 & -0.56 \\
Total PSI score & -0.45 & 0.51 & 0.45 & -0.61 \\
\hline
\end{tabular}

Note: $p$-value $<0.001$ for all correlation coefficients.

\subsection{Differences in Sex, Age and Years of Working Experience at School}

Significantly lower values on all PSI subscales, along with total PSI score, were found in men compared with women (Table 4), thus indicating higher confidence in their problem-solving ability. Effect sizes of the sex differences were 0.24 for Problem-Solving Confidence, 0.09 for Approach-Avoidance Style, 0.35 for Personal Control, 0.22 for total score and were mainly low. Furthermore, all PSI subscales and total PSI score were found lower as age increased $(p<0.001$ for all pairwise comparisons after Bonferroni correction), indicating that older teachers felt more skilled in problem-solving. Effect sizes of the differences between those aged less than 40 and those aged more than 50, were 0.48 for Problem-Solving Confidence, 0.41 for Approach-Avoidance Style, 0.43 for Personal Control and 0.49 for total score. Mean values of the PSI total score by sex and age groups are shown in Figure 1. Additionally, a low but significant and negative correlation was found between years of working experience at school and PSI subscales, as well as total PSI score, giving further evidence that older teachers had greater confidence in their problem-solving abilities. 
Table 4. Differences in sex, age and years of working experience at school on the Problem Solving Inventory subscales.

\begin{tabular}{|c|c|c|c|c|c|c|c|c|}
\hline & $\begin{array}{l}\text { Problem } \\
\text { Solving } \\
\text { Confidence }\end{array}$ & & $\begin{array}{l}\text { Approach- } \\
\text { Avoidance } \\
\text { Style }\end{array}$ & & $\begin{array}{l}\text { Personal } \\
\text { Control }\end{array}$ & & $\begin{array}{l}\text { Total } \\
\text { PSI Score }\end{array}$ & \\
\hline & Mean (SD) & $p$ & Mean (SD) & $p$ & Mean (SD) & $p$ & Mean (SD) & $p$ \\
\hline \multicolumn{9}{|l|}{ Sex } \\
\hline Men & 24.1 (7.5) & $<0.001 *$ & 37.8 (11.5) & 0.018 * & $13.3(5)$ & $<0.001 *$ & $75.2(21.1)$ & $<0.001 *$ \\
\hline Women & $26.0(7.8)$ & & $38.8(11.9)$ & & $15.1(5.1)$ & & $79.9(21.7)$ & \\
\hline \multicolumn{9}{|l|}{ Age } \\
\hline$\leqslant 40$ & $27.3(8.0)$ & $<0.001 * *$ & $41.0(11.8)$ & $<0.001^{* *}$ & $15.6(5.1)$ & $<0.001 * *$ & 83.9 (21.7) & $<0.001 * *$ \\
\hline $41-49$ & $25.1(7.4)$ & & $37.9(11.5)$ & & $14.5(5)$ & & $77.4(20.9)$ & \\
\hline$\geqslant 50$ & 23.6 (7.5) & & 36.2 (11.6) & & $13.4(5.2)$ & & $73.3(21.2)$ & \\
\hline $\begin{array}{l}\text { Years of working } \\
\text { experience atschool }\end{array}$ & $\mathrm{r}=-0.15$ & $<0.001 \ddagger$ & $\mathrm{r}=-0.12$ & $<0.001 \ddagger$ & $\mathrm{r}=-0.12$ & $<0.001 \ddagger$ & $\mathrm{r}=-0.15$ & $<0.001 \ddagger$ \\
\hline
\end{tabular}

* Student's t-test; ${ }^{* *}$ ANOVA; $\ddagger$ Pearson correlation coefficient $(\mathrm{r})$.

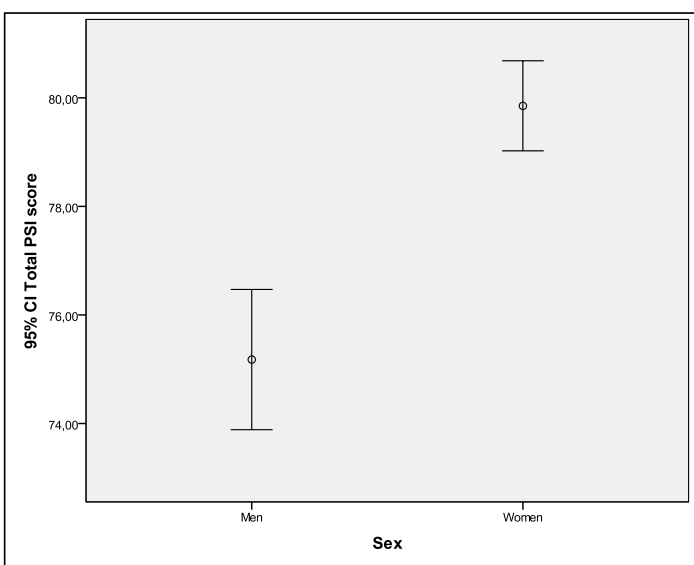

(a)

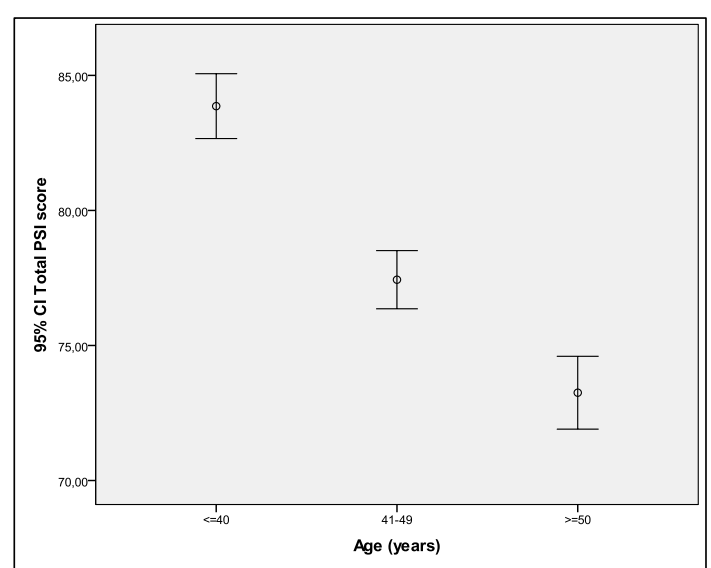

(b)

Figure 1. Error bars for Problem Solving Inventory (PSI) total score by (a) sex; and (b) age groups.

\section{Discussion}

The Problem Solving Inventory consists of three subscales, reflecting three distinct dimensions of problem-solving abilities, Problem-Solving Confidence, Approach-Avoidance Style and Personal Control. The purpose of the presented study was to successfully test the psychometric properties of the Greek version of the PSI in a sample of adults, specifically educators of all teaching levels and specialties. The confirmatory factor analysis indeed corroborated the bi-level model by Heppner et al. [18]. Specifically, all PSI items had high loadings both on one of the three first-order factors (i.e., PSC, AAS, and PC) and on the second-order factor, the general factor (i.e., PSI). Thus, the three dimensions of problem-solving emerged as three separate factors, as the corresponding items loaded to each factor clearly as anticipated. The RMSEA value was 0.030 , whereas the CFI and GFI values were 0.97 and 0.96 , respectively. The chi-square test of the model was high, something that was predicted due to our large sample size [35].

The internal consistency reliability of the three PSI subscales is similar to the one reported by the original inventory's manufacturers [8] and by other researchers $[12,17,18]$. All the PSI subscales had a satisfactory reliability standard that ranged from 0.79 to 0.91 . Moreover, all the PSI subscales significantly and positively correlated with each other. Problem-Solving Confidence was positively linked to both Approach-Avoidance Style and Personal Control at a moderate degree, which was 
also true for the correlation between the two latter subscales, a finding similar to that reported by the inventory's manufacturers [8] and other researchers [18].

In an attempt to show the convergent validity of the PSI we proceeded with a correlation analysis of the PSI subscales with the IPC LOC scale and the RSES. Despite the fact that all the correlation coefficients were moderate, they were all statistically significant. It is important to note again that low scores on each factor and on the total PSI score are considered more functional. All the PSI subscales correlated negatively with Internality of the IPC LOC scale and with the self-esteem scale, meaning that as the problem-solving confidence, the approach style and the personal control increased, so did the internal locus of control and the self-esteem. Moderate positive correlations were found between all the PSI subscales and both Powerful Others and Chance, indicating that as the problem-solving confidence, the approach style and the personal control increased, the attribution of control to others and chance decreased. Similar to our results, problem-solving confidence has been associated with an internal locus of control $[8,24]$ and a high self-esteem [1,9], from the inception of the PSI.

Approach-Avoidance Style had the highest mean score among all three PSI subscales, followed by Problem-Solving Confidence and Personal Control, which is in accordance with the inventory's manufacturers [8]. Men scored lower on all three subscales and on the total PSI score, thus appearing to perceive themselves as better problem-solvers. These gender differences did not emerge in previous studies $[13,17,37,38]$. One study even found that women scored lower on the Problem-Solving Confidence, incicating higher beliefs regarding their ability than men [17], which contradicts our results that men appraise themselves as being more confident than women in solving their personal problems. It could be hypothesized that women scored lower than men on the PSI due to their tendency to be more external than males on most locus of control measures [39]. Moreover, one has to consider that age, as well as the profession, could be a cause creating differences among samples, since the above mentioned previous studies were carried out in students. However, future research should investigate not only the possible differences based on biological sex, but also other gender-related variables that arise, such as gender roles deriving from various cultures, class level, etc.

All the subscales revealed differences concerning the age of the participants. As age increased, the scores on all three PSI subscales decreased, thus suggesting higher confidence concerning problem-solving skills. This finding is in agreement with studies which concluded that older adults tend to perform better on the PSI total score [40,41]. Older educators perceive themselves as better problem-solvers and are more confident about their specific skills. They tend to rather approach than avoid problems and they feel that they have control over their life's circumstances. The negative relation found between PSI and years of working experience further supports the finding that age and therefore larger working experience provides educators with the confidence and control needed in order to deal effectively with everyday problems.

\section{Strengths and Limitations}

There are two strong points in the present study; its large sample and the inclusion of educators of all teaching levels and specialties. Moreover, this study was able to confirm the three-dimensional model that was introduced by Heppner and Petersen [8].

Nevertheless, there are some limitations in it. Since its design was cross-sectional, the PSI's sensitivity to change over time was not examined. In addition, test-retest reliability was also not tested in the current study.

\section{Conclusions}

According to the results of the present study, the PSI appears to be a reliable and valid instrument for measuring confidence in problem-solving skills in Greek educators, while providing substantial support for three different dimensions of problem-solving abilities.

Acknowledgments: We would like to thank all the participating teachers who took the time to complete the online questionnaire, thus contributing significantly to our study. 
Author Contributions: N.K. designed and conducted the study, along with V.X. and M.T., and with the supervision of V.K. N.K. provided the statistical analysis, drafted the manuscript, and together with the other authors reviewed its final form.

Conflicts of Interest: The authors declare no conflict of interest.

\section{Abbreviations}

The following abbreviations are used in this manuscript:

$\begin{array}{ll}\text { CFA } & \text { Confirmatory Factor analysis } \\ \text { CFI } & \text { Comparative Fit Index } \\ \text { GFI } & \text { Goodness of Fit Index } \\ \text { IPC LOC Scale } & \text { Internality, Powerful Others and Chance Multidimensional Locus of Control Scale } \\ \text { PSI } & \text { Problem Solving Inventory } \\ \text { RMSEA } & \text { Root Mean Square Error of Approximation } \\ \text { RSES } & \text { Rosenberg Self-Esteem Scale }\end{array}$

\section{References}

1. Paul P. Heppner, and Charles E. Baker. "Applications of the Problem Solving Inventory." Measurement and Evaluation in Counseling Development 29 (1997): 229-41.

2. Paul P. Heppner, Thomas E. Witty, and Wayne A. Dixon. "Problem-solving appraisal and human adjustment: A review of 20 years of research using the problem solving inventory." Counseling Psychologist 32 (2004): 344-28. [CrossRef]

3. Thomas J. D'Zurilla, and Marvin R. Goldfried. "Problem solving and behavior modification." Journal of Abnormal Psychology 78 (1971): 107-26. [CrossRef] [PubMed]

4. Erin Largo-Wight, Michael P. Peterson, and William W. Chen. "Perceived problem solving, stress, and health among college students." American Journal of Health Behavior 29 (2005): 360-70. [CrossRef] [PubMed]

5. Paul P. Heppner. "Problem-Solving Inventory." In Measures for Clinical Practice : A Sourcebook. Volume 2: Adults, 3rd ed. Edited by Kevin J. Corcoran and Joel Fischer. New York: The Free Press, 1981, pp. 591-94.

6. Arthur M. Nezu. "Problem solving and behavior therapy revisited." Behavior Therapy 35 (2005): 1-33. [CrossRef]

7. Lynda Butler, and Donald Meichenbaum. "The assessment of interpersonal problem-solving skills." In Assessment Strategies for Cognitive-Behavioral Interventions. Edited by Philip C. Kendall and Steven D. Hollon. New York: Academic Press, 1981, pp. 197-225.

8. Paul P. Heppner, and Chris H. Petersen. "The development and implications of a personal problem solving inventory." Journal of Counseling Psychology 29 (1982): 66-75. [CrossRef]

9. Paul P. Heppner, and Yu-Wei Wang. "Problem-solving appraisal and psychological adjustment." In Oxford Handbook of Positive Psychology, 2nd ed. Edited by Charles R. Snyder and Shane J. Lopez. New York: Oxford University Press, 2009, pp. 127-38.

10. Steven G. LoBello. “Test review of The Problem Solving Inventory." In The Eleventh Mental Measurements Yearbook. Edited by Jack J. Kramer and Jane Close Conoley. Lincoln: Buros Center for Testing, 1992, p. 6. Available online: http://marketplace.unl.edu/buros/ (accessed on 11 December 2015).

11. C. J. Camp. "Test review of The Problem Solving Inventory." In The Eleventh Mental Measurements Yearbook. Edited by Jack J. Kramer and Jane Close Conoley. Lincoln: Buros Center for Testing, 1992, p. 5. Available online: http:/ / marketplace.unl.edu/buros/ (accessed on 11 December 2015).

12. Laura Nota, Paul P. Heppner, Salvatore Soresi, and Mary J. Heppner. "Examining cultural validity of the Problem-Solving Inventory (PSI) in Italy." Journal of Career Assessment 17 (2009): 478-94. [CrossRef]

13. Yu-Ping Huang, and Lisa Y. Flores. "Exploring the validity of the Problem-Solving Inventory with Mexican American high-school students." Journal of Career Assessment, 2011. [CrossRef]

14. Sammy K. Cheng, and David J. Lam. "Relationships among life stress, problem solving, self-esteem, and dysphoria in Hong Kong adolescents: Test of a model." Journal of Social and Clinical Psychology 16 (1997): 343-55. [CrossRef]

15. Samuel O. Salami, and Oyesoji A. Aremu. "Relationship between problem-solving ability and study behaviour among school-going adolescents in southwestern Nigeria." Electronic Journal of Research in Educational Psychology 4 (2006): 139-54. 
16. Gavin Beccaria, and M. Anthony Machin. "Examining the validity of the problem solving inventory in Australia." Paper presented at the 27th International Congress of Applied Psychology (ICAP 2010), Australian Psychological Society, Flinders Lane, Australia, 11-16 July 2010.

17. Nail Sahin, Nesrin H. Sahin, and Paul P. Heppner. "Psychometric properties of the problem solving inventory in a group of Turkish university students." Cognitive Therapy and Research 17 (1993): 379-96. [CrossRef]

18. Paul P. Heppner, Tyrone Brian Pretorius, Meifen Wei, Dong-gwi Lee, and Yu-Wei Wang. "Examining the generalizability of problem-solving appraisal in Black South Africans." Journal of Counseling Psychology 49 (2002): 484-98. [CrossRef]

19. Helen A. Neville, Paul P. Heppner, and Li-Fei Wang. "Relations among racial identity attitudes, perceived stressors, and coping styles in African American college students." Journal of Counseling and Development 75 (1997): 303-11. [CrossRef]

20. Diane Marcotte, Michel Alain, and Marie-Josee Gosselin. “Gender differences in adolescent depression: Gender-typed characteristics or problem-solving skills deficits? " Sex Roles 41 (1999): 31-48. [CrossRef]

21. Gabriel Roşeanu, and Marian Mihai. "Adaptation study of the Problem Solving Inventory on the Romanian population." International Journal of Education and Psychology in the Community 2 (2012): 89-101.

22. Paul P. Heppner, Mary Kampa, and Lee Brunning. "The relationship between problem-solving self-appraisal and indices of physical and psychological health." Cognitive Therapy and Research 11 (1987): 155-68. [CrossRef]

23. Julian B. Rotter. "Generalized expectancies for problem solving and psychotherapy." Cognitive Therapy and Research 2 (1978): 1-10. [CrossRef]

24. Ann H. Baumgardner, Paul P. Heppner, and Robert M. Arkin. "Role of causal attribution in personal problem solving." Journal of Personality and Social Psychology 50 (1986): 636-43. [CrossRef]

25. Hanna Levenson. "Reliability and Validity of the I, P, and C Scales-A Multidimensional View of Locus of Control." 1973. Available online: http://files.eric.ed.gov/fulltext/ED087791.pdf (accessed on 1 September 2015).

26. Hanna Levenson. "Activism and Powerful Others: Distinctions within the Concept of Internal-External Control." Journal of Personality Assessment 38 (1974): 377-83. [CrossRef]

27. Hanna Levenson. "Differentiating among internality, powerful others, and chance." In Research with the Locus of Control Construct: Vol. 1, Assessment Methods. Edited by Herbert M. Lefcourt. New York: Academic Press, 1981, pp. 15-63.

28. Ntina Kourmousi, Vasiliki Xythali, and Vasilios Koutras. "Reliability and Validity of the Multidimensional Locus of Control IPC Scale in a Sample of 3668 Greek Educators." Social Sciences 4 (2015): 1067-78. [CrossRef]

29. Morris Rosenberg. Society and the Adolescent Self-Image. Princeton: Princeton University Press, 1965.

30. David P. Schmitt, and Jüri Allik. "Simultaneous Administration of the Rosenberg Self-Esteem Scale in 53 Nations: Exploring the Universal and Culture-Specific Features of Global Self-Esteem." Journal of Personality and Social Psychology 89 (2005): 623-42. [CrossRef] [PubMed]

31. Panhellenic School Network. Available online: http://www.sch.gr/ (accessed on 3 April 2014).

32. Sch.gr. "Teachers' Survey." Available online: http://www.sch.gr/96-announces/3004-2014-04-23-09-40-07 (accessed on 3 April 2014).

33. Guillermo Solano-Flores, Eduardo Backhoff, and Luis Ángel Contreras-Niño. "Theory of Test Translation Error." International Journal of Testing 9 (2009): 78-91. [CrossRef]

34. Fons van de Vijver, and Ronald K. Hambleton. "Translating tests: Some practical guidelines." European Psychologist 1 (1996): 89-99. [CrossRef]

35. Ralph O. Mueller. Basic Principles of Structural Equation Modelling. New York: Springer-Verlag, 2000.

36. Litze $\mathrm{Hu}$, and Peter M. Bentler. "Cutoff criteria for fit indexes in covariance structure analysis: Conventional criteria versus new alternatives." Structural Equation Modeling: A Multidisciplinary Journal 6 (1999): 1-55. [CrossRef]

37. Paul P. Heppner, Janet Hibel, Gary W. Neal, Charles L. Weinstein, and Fredric E. Rabinowitz. "Personal problem solving: A descriptive study of individual differences." Journal of Counseling Psychology 29 (1982): 580-90. [CrossRef]

38. Paul P. Heppner, and Thomas S. Krieshok. "An applied investigation of problem-solving appraisal, vocational identity, and career service requests, utilization, and subsequent evaluations." The Vocational Guidance Quarterly 31 (1983): 240-49. [CrossRef] 
39. Adrian C. Sherman, Graham E. Higgs, and Robert L. Williams. "Gender differences in the locus of control construct." Psychology and Health 12 (1997): 239-48. [CrossRef]

40. Patricia A. Haught, Lee Ann Hill, Anne H. Nardi, and Richard T. Walls. "Perceived ability and level of education as predictors of traditional and practical adult problem solving." Experimental Aging Research 26 (2000): 89-101. [PubMed]

41. Bonnie McLean Wright, David Mitchell Carscaddon, and Steven Dennis Lambert. "Sex, Education, Age, and Cautiousness: Implications for Counselors." Adultspan Journal 2 (2000): 113-22. [CrossRef]

(C) 2016 by the authors; licensee MDPI, Basel, Switzerland. This article is an open access article distributed under the terms and conditions of the Creative Commons Attribution (CC-BY) license (http://creativecommons.org/licenses/by/4.0/). 